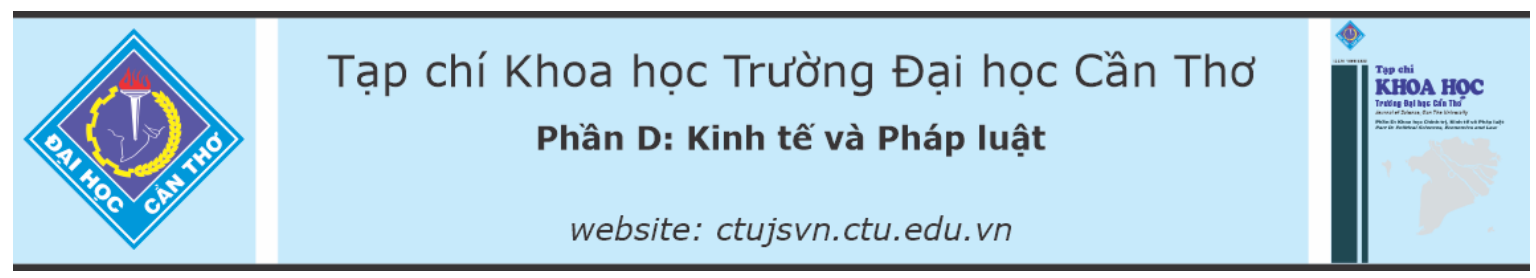

DOI:10.22144/ctu.jvn.2021.195

\title{
PHÂN TÍCH HIỆ QUẢ KỸ THUẬT CỦA NGHỀ LƯỚI KÉO Ở VÙNG BIỂN ĐÔNG ĐỒNG BẰNG SÔNG CỦU LONG
}

\author{
Đặng Thị Phượng ${ }^{1 *}$, Nguyễn Thanh Long ${ }^{1}$ và Huỳnh Việt Khải ${ }^{2}$ \\ ${ }^{1}$ Khoa Thủy sản, Truoòng Đại học Cần Tho \\ ${ }^{2}$ Khoa Kinh tế, Truờng Đại học Cần Tho \\ "Nguời chịu trách nhiệm về bài viết: Đặng Thị Phurơng (email: thiphuong@ctu.edu.vn)
}

\section{Thông tin chung:}

Ngày nhận bài: 22/06/2021

Ngày nhận bài sưa: 31/07/2021

Ngày duyệt đăng: 25/12/2021

Title:

Analysis of the technical efficiency of the trawl net in the East Sea of the Mekong Delta

\section{Tù khóa:}

Hiệu quả kỹ thuật, luới kéo, tài chinh

Keywords:

Finance, technical efficiency, trawl-net

\begin{abstract}
This study is to estimated the technical efficiency of the trawl net in the East Sea of the Mekong Delta using the approach of the translog stochastic frontier production function model. Data were collected through interviewing 60 vessels in Soc Trang and Bac Lieu provinces. The results showed that the average fishing production of the trawl net was $643 \mathrm{~kg} /$ trip and 18.9 tons/year with the time for each trip was about 4 days. The total cost for trawl net was 316 million VND/year and income was 608 million VND/year. The average technical efficiency of trawling was $86.3 \%$. Captain-related factors such as experience, education, and age; vessel age, and production capital have an impact on the technical efficiency of the trawl net. To improve the technical efficiency of the trawl net industry, it is necessary to focus on training the captains, upgrading and exchanging large ships, and linking the market channels for the consumption of caught fishery products.
\end{abstract}

\section{TÓM TẮT}

Bài viết uớc lượng hiệu quả kỹ thuật của nghề luới kéo ở vùng biển Đông Đồng bằng sông Củu Long bằng mô hình hàm sản xuất biên ngẫu nhiên dạng translog. Số liệu được thu thập thông qua phỏng vấn trực tiếp 60 ngu dân của nghề luới kéo ở tỉnh Sóc Trăng và Bạc Liêu. Kết quả cho thấy sản luợng thủy sản khai thác của nghề luới kéo bình quân là 643 kg/chuyến biển và 18,9 tấn/năm với thời gian cho mỗi chuyến biển là khoảng 4 ngày. Tổng chi phí cho nghề luoói kéo là 316 triệu đồng/năm và doanh thu là 608 triệu đồng/năm. Mức hiệu quả kỹ thuật của nghề lưới kéo trung bình là $86,3 \%$. Các yếu tố liên quan đến thuyền trưởng nhu kinh nghiệm, trình độ học vấn và tuổi; tuổi của tàu và nguồn vốn sản xuất có tác động đến hiệu quả kỹ thuật của nghề luới kéo. Để cải thiện hiệu quả kỹ thuật của nghề luới kéo cần chú trọng việc đào tạo nguời thuyền truởng, nâng cấp, hoán đổi tàu lớn và liên kết kênh thị truờng tiêu thụ sản phẩm thủy sản khai thác.

\section{GIỚI THIỆU}

Hoạt động khai thác thủy sản ở Việt Nam có vai trò góp phần đáng kể cho sự phát triển kinh tế, với sản lượng thủy sản khai thác từ 3,1 triệu tấn và giá trị xuất khẩu là 2,2 tỷ USD trong năm 2015 (Hiệp hội Chế biến và Xuất khẩu thủy sản Việt Nam, 2018) 
và tăng đến 3,8 triệu tấn, mang lại giá trị xuất khẩu là 3,2 tỷ USD trong năm 2019 (Hiệp hội Chế biến và Xuất khẩu thủy sản Việt Nam, 2020). Ngoài ra, khai thác thủy sản đã tạo ra một nguồn thực phẩm lớn cho tiêu thụ trong nước và tạo việc làm trực tiếp và gián tiếp cho cộng đồng dân cư vùng ven biển. Đồng bằng sông Cửu Long (ĐBSCL) là vùng có dân số 17,8 triệu người, chiếm $18,8 \%$ tổng dân số của cả nước (Tồng cục Thống kê Việt Nam, 2020) với hơn $70 \%$ dân số sống ở vùng nông thôn và vùng ven biển. ĐBSCL có sản lượng thủy sản khai thác thủy sản chiếm khoảng $40 \%$ tổng sản lượng thủy sản khai thác của Việt Nam và trong đó sự đóng góp từ sản lượng hải sản là 26,4\% (Tổng cục Thống kê Việt Nam, 2020), vì vậy cộng đồng dân cư ở vùng này phụ thuộc rất lớn vào tài nguyên thiên nhiên, trong đó có hoạt động khai thác hải sản.

Các tỉnh ven biển thuộc ĐBSCL, trong đó có tỉnh Sóc Trăng và Bạc Liêu là những tỉnh phát triển mạnh về hoạt động nuôi trồng và khai thác thủy sản. Nghề lưới kéo và lưới rê là hai loại nghề khai thác phổ biến, chiếm $60,9 \%$ tổng lượng tàu của vùng. Nghề lưới kéo là nghề khai thác thủy sản chiếm tỷ trọng cao nhất, với $40,9 \%$ số lượng tàu thuyền khai thác của vùng. Quy mô khai thác thủy sản ở ĐBSCL là quy mô nhỏ và khai thác ven bờ, chiếm khoảng $53,3 \%$ số tàu đánh cá. Ngoài ra, thu nhập của hộ ngư dân khai thác được tích lũy chính từ hoạt động khai thác thủy sản với hơn $80 \%$ tổng thu nhập của hộ (Huỳnh Văn Hiền và ctv., 2019). Trong khi đó, định hướng quy hoạch phát triển ngành thủy sản cho thấy lĩnh vực khai thác thủy sản được đặt ra là tổ chức lại sản xuất trong khai thác hải sản phù hợp với từng nhóm nghề và ngư trường, trong đó nghề lưới kéo ven bờ được khuyến khích hạn chế phát triển và không cho đóng mới cũng như khuyến khích các tàu lưới kéo ven bờ khai thác kém hiệu quả chuyển đổi nghề, đặc biệt phát triển khai thác xa bờ. Để có cơ sở sắp xếp và phát triển nghề khai thác thủy sản phù hợp với chính sách và điều kiện của ngư dân, việc cung cấp thông tin và tính toán hiệu quả hoạt động khai thác thủy sản, đặc biệt là hiệu quả kỹ thuật của nghề lưới kéo ven bờ là cần thiết.

\section{PHƯƠNG PHÁP NGHIÊN CÚU}

\subsection{Phương pháp thu thập số liệu}

Nghiên cứu sử dụng số liệu được thu thập bằng cách phỏng vấn trực tiếp các hộ ngư dân làm nghề lưới kéo có chiều dài tàu từ $12 \mathrm{~m}$ đến dưới $15 \mathrm{~m}$ ở hai tỉnh Bạc Liêu và Sóc Trăng (đại diện cho vùng biển Đông ĐBSCL) từ tháng 01 đến tháng 12 năm 2020. Vùng khai thác thủy sản của tàu lưới kéo có chiều dài từ $12 \mathrm{~m}$ đến dưới $15 \mathrm{~m}$ là vùng lộng. Các tàu khai thác được chọn phỏng vấn một cách ngẫu nhiên dựa vào danh sách tàu lưới kéo có chiều dài từ $12 \mathrm{~m}$ đến dưới $15 \mathrm{~m}$ được cung cấp từ Chi cục Thủy sản tỉnh Bạc Liêu và Sóc Trăng. Tổng số quan sát là 60 tàu, trong đó tỉnh $\mathrm{Bạc}$ Liêu là 30 tàu và tỉnh Sóc Trăng là 30 tàu. Trong quá trình phỏng vấn, các cán bộ địa phương hướng dẫn tìm các hộ đã được chọn ngẫu nhiên để phỏng vấn. Các số liệu về khía cạnh kỹ thuật và tài chính được ghi nhận ở năm 2019.

\subsection{Phương pháp phân tích số liệu}

Hiệu quả kỹ thuật là trình độ kỹ thuật của người sản xuất trong việc sử dụng các yếu tố đầu vào trong quá trình sản xuất để đạt năng suất hoặc sản lượng tối đa với các yếu tố đầu vào hiện có, hoặc đạt lượng đầu vào tối thiểu với năng suất hoặc sản lượng hiện có (Coelli et al., 2005). Mô hình ước lượng hiệu quả kỹ thuật trong nông nghiệp có nhiều dạng, trong đó mô hình phân tích biên ngẫu nhiên được các nhà nghiên cứu trong hoạt động khai thác thủy sản ứng dụng phổ biến. Dạng hàm sản xuất có dạng tổng quát (1) như sau (Coelli et al., 2005):

$$
y=\exp \left[\beta_{0}+\sum_{\mathrm{i}=1}^{\mathrm{n}} \beta_{i} \ln \mathrm{x}_{\mathrm{i}}+1 / 2 \sum_{i=1}^{n} \sum_{k=1}^{n} \beta_{i k} \ln \mathrm{x}_{\mathrm{i}} \ln \mathrm{x}_{\mathrm{k}}\right]
$$

Thông qua định nghĩa và mô hình ước lượng về hiệu quả kỹ thuật cho thấy yếu tố đầu ra được đo lường với yếu tố sản lượng, nhưng trong hoạt động khai thác thủy sản thường được sử dụng giá trị thay thế cho yếu tố lượng do đặc thù của nghề khai thác thủy sản. Các nghiên trước đây như Herrero et al. (2006); Jamnia et al. (2014); Kompas et al. (2004); Pascoe and Coglan (2002); Sharma and Leung (1999); Tingley et al. (2005); Truong et al. (2011) đã sử dụng đầu ra $(y)$ là doanh thu, thay cho đầu ra là sản lượng, mặc dù giá trị này có thể chịu tác động của giá cả. Nguyên nhân là một số nghề khai thác thủy sản (ví dụ nghề lưới kéo) là nghề khai thác được rất nhiều loài, kích cỡ khác nhau. Giá bán có rất nhiều mức với ứng từng loài và kích cỡ khác nhau. Chính vì vậy, doanh thu của tàu được dùng để ước lượng hiệu quả kỹ thuật của nghề lưới kéo ở vùng biển Đông ĐBSCL.

Mô hình nghiên cứu thực nghiệm để ước lượng hiệu quả kỹ thuật của tàu lưới kéo vùng biển Đông ĐBSCL có dạng hàm Translog như sau:

$\ln Y_{i}=\beta_{0}+\beta_{1} \ln X_{1}+\beta_{2} \ln X_{2}+\beta_{3} \ln X_{3}+1 / 2$ $\beta_{4}\left(\ln X_{1}\right)^{2}+1 / 2 \beta_{5}\left(\ln X_{2}\right)^{2}+1 / 2 \beta_{6}\left(\ln X_{3}\right)^{2}+\beta_{7} \ln X_{1} * \ln X_{2}+$ $\beta_{8} \ln X_{1} * \ln X_{3}+\beta_{9} \ln X_{2} * \ln X_{3}+v_{j}-u_{j}$

Trong đó: $Y_{i}$ là doanh thu tính trong một năm (triệu đồng/năm); $\beta_{0}$ là hệ số chặn của hàm sản xuất biên ngẫu nhiên; $\beta_{1,2, \ldots ., 9}$ là hệ số tương quan thứ i ứng 
với biến độc lập là: $X_{l}$ : số ngày khai thác (ngày/năm); $X_{2}$ : lao động trên tàu (người); và $X_{3}$ : Chiều dài ngư cụ $(\mathrm{m}) ; v_{j}-u_{j}$ là sai số hỗn hợp của mô hình.

Mô hình các yếu tố ảnh hưởng đến phi hiệu quả kỹ thuật được viết dưới dạng sau:

$$
u_{j}=\delta_{0}+\sum_{i=1}^{6} \delta_{i} \mathrm{Z}_{i j}+\omega_{j}
$$

Trong đó: $u_{j}$ là phi hiệu quả kỹ thuật của tàu khai thác nghề lưới kéo; $Z_{1,2, \ldots 6}$ là các đặc điểm về tàu khai thác và nhân lực khai thác, cụ thể là $Z_{I}$ : kinh nghiệm khai thác (năm); $Z_{2}$ : trình độ học vấn của thuyền trưởng (lớp); $Z_{3}$ : công suất máy tàu $(\mathrm{CV}) ; Z_{4}$ : tuổi thuyền trưởng (năm); $Z_{5}$ : Tuổi của tàu (năm); $Z_{6}$ : nguồn vốn (1- Có vay vốn; 0 - Không).

Mô hình (2) và (3) được ước lượng đồng thời bằng phương pháp ước lượng cực đại (MLE - maximum likelihood estimation) để tìm ra các hệ số ước lượng của các mô hình. Phần mềm FRONTIER 4.1 được sử dụng để ước lượng hiệu quả kỹ thuật trong sản xuất. Hệ số hiệu quả kỹ thuật theo mô hình phân tích biên ngẫu nhiên nằm trong khoảng từ 0 đến bằng 1 . Nếu hệ số này bằng 1 có nghĩa là hộ sản xuất đạt được hiệu quả kỹ thuật tối ưu, nhỏ hơn 1 có nghĩa là hộ sản xuất chưa đạt được hiệu quả kỹ thuật tối ưu. Hệ số hiệu quả kỹ thuật được ước lượng từ sự khác nhau giữa lượng đầu ra thực sự và đầu ra tính toán $\left(Y_{i}-\hat{Y}_{i}\right)$. Hiệu quả kỹ thuật được tính theo công thức:

$\mathrm{TE}_{\mathrm{i}}=$ Mức đầu ra thực tế của tàu $\mathrm{i}\left(\mathrm{Y}_{\mathrm{i}}\right) /$ Mức đầu ra tối đa của tàu $\mathrm{i}\left(\mathrm{Y}_{\mathrm{i}}^{*}\right)$

Kiểm định giả thuyết đối với mô hình sản xuất biên ngẫu nhiên và mô hình phi hiệu quả sản xuất được tổng hợp ở Bảng 1.

\section{Bảng 1. Kiểm định giả thuyết lựa chọn mô hình và phi hiệu quả kỹ thuật}

\begin{tabular}{lrrrl}
\hline Kiểm định & LR & Bậc tự do & Giá trị phân phối $\chi^{2}$ & Kết luận \\
\hline $\mathrm{H}_{0}: \beta_{4}=\beta_{5}=\ldots=\delta_{9}=0$ & 29,4426 & 6 & $16,812^{* * *}$ & Bác bỏ $\mathrm{H}_{0}$ \\
$\mathrm{H}_{0}: \Upsilon=\delta_{0}=\delta_{1}=\ldots=\delta_{6}=0$ & 24,3326 & 10 & $23,209^{* * *}$ & Bác bỏ $\mathrm{H}_{0}$ \\
$\mathrm{H}_{0}: \delta_{1}=\delta_{2}=\ldots \ldots=\delta_{6}=0$ & 24,3326 & 6 & $16,812^{* * *}$ & Bác bỏ $\mathrm{H}_{0}$ \\
\hline
\end{tabular}

Chú thich: ${ }^{* * *},{ }^{* *}$, và ${ }^{*}$ biểu diến các múc ý nghĩa 1\%, 5\%, và 10\%; LR: Likelihood ratio

Công thức chung tính giá trị kiểm định $\mathrm{LR}$ (likelihood ratio) $=-2\left[\left(L\left(H_{0}\right)-L\left(H_{1}\right)\right]\right.$, với $\mathrm{L}\left(H_{0}\right)$ và $\mathrm{L}\left(H_{l}\right)$ là các giá trị log-likelihood của mô hình đối chiếu $\left(\mathrm{H}_{0}\right)$ và mô hình nghiên cứu $\left(\mathrm{H}_{1}\right)$ tương ứng. Thứ nhất là giả thuyết mô hình Cobb-Douglas được lựa chọn $\left(\beta_{4}=\beta_{5}=\ldots=\delta_{9}=0\right)$. Thứ hai là kiểm định giả thuyết không có kém hiệu quả kỹ thuật và các yếu tố ảnh hưởng đến phi hiệu quả $\left(\Upsilon=\delta_{0}=\delta_{1}=\right.$ $\ldots=\delta_{6}=0$ và $\left.\delta_{1}=\delta_{2}=\ldots=\delta_{6}=0\right)$. Kết quả Bảng 1 cho thấy các giả thuyết $\mathrm{H}_{0}$ được bác bỏ, tức là doanh thu nghề lưới kéo chịu tác động bởi yếu tố thời tiết, môi trường và sự quản lý của con người.

\section{KẾT QUẢ VÀ THẢO LUẬN}

\section{1. Đặc điểm khai thác thủy sản của nghề lưới kéo}

\subsection{1. Đặc điểm lao động trên tàu khai thác}

Thuyền trưởng tàu cá là người có quyết định cao nhất trên tàu, điều kiển tàu đến ngư trường khai thác, quyết định thả lưới, thu lưới, điều khiển ngư cụ khai thác, máy móc trên tàu (Nguyễn Trọng Tuy và ctv., 2011). Bảng 2 cho thấy thuyền trưởng ở nghề lưới kéo có độ tuổi khá lớn, số năm kinh nghiệm của họ trong khai thác thủy sản tương đối cao (20,3 năm). Phần lớn các thuyền trưởng tham gia lao động trên biển có học vấn không cao, tập trung ở mức tiểu học $(58,3 \%)$, kế đến là trung học cơ sở $(30 \%)$ và trung học phổ thông $(10 \%)$. Điều này cho thấy các thuyền trưởng có thể hạn chế trong việc học tập và ứng dụng công nghệ hiện đại vào hoạt động khai thác thủy sản.

Số lượng lao động trên một tàu khai thác thủy sản nghề lưới kéo không cao, khoảng 2 đến 5 người trên một tàu, chủ yếu lao động là nam vì do đặc điểm và tính chất công việc trên biển, đòi hỏi người lao động phải có sức khỏe, mới có thể lao động trên tàu và ứng phó các tình huống trên biển. Lực lượng lao động trên tàu chủ yếu là lao động từ gia đình với khoảng $60 \%$ trong tổng số lao động trên tàu và số lao động còn lại được thuê mướn tại địa phương $(1,4$ người/tàu). Điều này cho thấy nghề lưới kéo ven bờ đã góp phần tạo công ăn việc làm cho các thành viên trong gia đình của chủ tàu và người dân địa phương, đây cũng là nghề giúp người dân ven biển tham gia lao động tăng thu nhập cho gia đình. Tuy nhiên, tình trạng thiếu lao động trong khai thác thủy sản là vấn đề được các chủ tàu quan tâm, do sự phát triển của các khu và cụm công nghiệp ven biển nên đã thu hút nhiều lao động làm thiếu hụt lao động trong nghề khai thác thủy sản. Đôi khi có nhiều lao động tạm ứng tiền lương trước, đến khi tàu đi khai thác thì các 
lao động này bỏ việc, không chịu tham gia. Việc này gây rất nhiều khó khăn cho tàu khai thác thủy sản vì thiếu lao động nên không thể ra khơi đánh cá hoặc hoạt động với hiệu quả không cao.

\section{Bảng 2. Lao động trên tàu của nghề lưới kéo}

\begin{tabular}{lrrr}
\hline Thông tin & Trung bình (n=60) & Độ lệch chuẩn & Dao động \\
\hline Tuổi của thuyền trưởng (năm) & 43,6 & 7,8 & $27,0-66,0$ \\
Kinh nghiệm khai thác (năm) & 20,3 & 7,4 & $4,0-39,0$ \\
Trình độ học vấn (lớp) & 5,4 & 2,7 & $0,0-11,0$ \\
Tồng lao động trên tàu (người) & 3,7 & 0,82 & $2,0-5,0$ \\
Số lao động thuê (người) & 1,4 & 0,83 & $0,0-4,0$ \\
\hline
\end{tabular}

(Nguồn: Số liệu khảo sát, 2020)

\subsubsection{Thông số tàu và ngu cu khai thác}

Tàu lưới kéo có chiều dài thân tàu trung bình $12,9 \mathrm{~m}$ với trọng tải của tàu tương đối nhỏ, bình quân là 8,1 tấn và công suất máy tàu là $58,9 \mathrm{CV}$. Chính vì vậy, tàu thích hợp cho chuyến biển ngắn và khai thác vùng lộng. Tùy thuộc vào điều kiện kinh tế của hộ ngư dân mà việc đầu tư tàu khai thác lúc ban đầu có thể là tàu mới hoặc là tàu đã qua sử dụng. Kết quả nghiên cứu cho thấy ngư dân có số năm sở hữu tàu hiện có hay còn gọi là tuổi của tàu là khoảng 7,5 năm, cao nhất là 15 năm và gần nhất là 3 năm.

Bảng 3. Đặc điểm tàu và ngư cụ khai thác của nghề lưới kéo

\begin{tabular}{lrrr}
\hline Thông tin & Trung bình $(\mathbf{n}=\mathbf{6 0})$ & Độ lệch chuẩn & Dao động \\
\hline 1. Tàu khai thác & & & \\
\hline Chiều dài tàu (m) & 12,9 & 0,8 & $12,0-14,9$ \\
Công suất của máy tàu (CV) & 58,9 & 20,8 & $27,0-97,0$ \\
Tải trọng của tàu (tấn) & 8,1 & 3,6 & $3,5-18,0$ \\
Tuổi của tàu (năm) & 7,5 & 2,4 & $3,0-15,0$ \\
\hline 2. Ngư cụ (lưới) & & & \\
\hline Chiều dài của lưới (m) & 23,9 & 6,4 & $10,0-35,0$ \\
Kích thước mắt lưới ở đụt $(\mathrm{mm})$ & 24,9 & 4,9 & $15,0-40,0$ \\
\hline
\end{tabular}

(Nguồn: Số liệu khảo sát, 2020)

Nghề lưới kéo có chiều dài ngư cụ (lưới) trung bình $23,9 \mathrm{~m}$ và lưới được sửa chữa thường xuyên do dễ bị rách. Kích thước mắt lưới có ảnh hưởng đến kích cỡ hải sản khai thác và tác động rất lớn đến nguồn lợi hải sản. Quy định kích thước mắt lưới ở bộ phận tập trung cá của Thông tư 19/2018 của Bộ Nông nghiệp và Phát triển nông thôn đối với nghể lưới kéo có chiều dài lớn nhất từ $12 \mathrm{~m}$ đến dưới 15 $\mathrm{m}$ là $34 \mathrm{~mm}$. So với quy định thì kích thước mắt lưới nghề lưới kéo ở vùng biển Đông ĐBSCL $(24,9$ mm) nhỏ hơn quy định, đây cũng là một trong những nguyên nhân có thể ảnh hưởng đến sự phát triển nguồn lợi thủy sản.

\subsubsection{Sản lương thủy sản khai thác}

Nghề lưới kéo có thể khai thác quanh năm, ngoại trừ thời gian có thời tiết xấu và sửa chữa tàu. Kết quả nghiên cứu cho thấy thời gian khai thác của nghề lưới kéo trong một năm trung bình 8,4 tháng/năm. Số chuyến ra khơi đánh bắt hải sản của ngư dân làm nghề lưới kéo trung bình 3,9 chuyến/tháng và mỗi chuyến biển kéo dài khoảng 4,2 ngày/chuyến.

Sản lượng khai thác của nghề lưới kéo đạt trung bình $643 \mathrm{~kg}$ /chuyến, tương ứng tổng sản lượng khai thác bình quân trên một năm là 18,9 tấn/năm và năng suất khai thác thủy sản được tính trên công suất máy tàu ở là $352 \mathrm{~kg} / \mathrm{CV} / \mathrm{năm}$. So với 7 năm trước đó, sản lượng và năng suất hải sản khai thác từ lưới kéo ở vùng biển Đông thấp hơn so với mặt bằng chung của nghể lưới kéo quy mô nhỏ ở toàn vùng ĐBSCL, khoảng $25,6 \%$ về sản lượng và $33,6 \%$ về năng suất khai thác (Nguyễn Trung Vẹn và ctv., 2013). 
Bảng 4. Thời gian và sản lượng thủy sản khai thác

\begin{tabular}{lrrr}
\hline Thông tin & $\begin{array}{r}\text { Trung } \\
\text { bình } \\
\text { (n=60) }\end{array}$ & $\begin{array}{r}\text { Độ } \\
\text { lệch } \\
\text { chuẩn }\end{array}$ & Dao động \\
\hline Số ngày khai thác cho một chuyến biển (ngày/chuyến) & 4,2 & 1,4 & $2-10$ \\
Số chuyến biển khai thác trong tháng (chuyến/tháng) & 3,9 & 1,5 & $2-10$ \\
Số tháng khai thác trong năm (tháng) & 8,4 & 2,0 & $4-12$ \\
Sản lượng khai thác cho một chuyến biển (kg/chuyến) & 642,8 & 282,0 & $72-1.750$ \\
Tổng sản lượng khai thác trong năm (kg/năm) & $18.896,4$ & $8.182,4$ & $5.760-45.700,2$ \\
Tổng số ngày khai thác trong năm (ngày/năm) & 125,4 & 45,7 & $48-240$ \\
Tổng số chuyến khai thác trong năm (chuyến/năm) & 31,8 & 14,8 & $8-120$ \\
Tỷ lệ cá tạp (\%) & 28,5 & 11,8 & $15,7-60$ \\
\hline
\end{tabular}

(Nguồn: Số liệu khảo sát, 2020)

\subsection{Hiệu quả tài chính của nghề lưới kéo}

Chi phí hoạt động khai thác của nghề lưới kéo cho một chuyến biển gồm có chi phí cố định và chi phí biển đổi. Chi phí khấu hao là các khoản chi từ chi mua vỏ tàu, máy tàu, ngư cụ (lưới) và các thiết bị hỗ trợ khai thác (máy định vị, máy đàm thoại) được tính cho một năm. Kết quả nghiên cứu cho thấy chi phí khấu hao hằng năm trung bình là 34,2 triệu đồng/năm, trong đó chi mua vỏ tàu và máy tàu khai thác chiếm khoảng $54 \%$, kế đến là chi phí chi cho ngư cụ với $41,1 \%$. Chi phí biến đổi của nghề lưới kéo chiếm một tỷ lệ lớn trong tổng chi phí hoạt động khai thác với trung bình là $88,4 \%$. Trong cơ cấu chi phí biến đổi của nghề lưới kéo, chi phí nhiên liệu (dầu, nhớt) chiếm tỷ lệ cao nhất với chiếm $52 \%$ so với tổng chi phí biến đổi của một chuyến biển, kế đến là tiền nhân công thuê (24\%), lương thực thực phẩm $(12 \%)$ và phần còn lại chi cho việc mua các nguyên liệu bảo quản sản phẩm khai thác như nước đá và các khoản cần thiết khác (Hình 1$)$. Kết quả cho thấy sự tương đồng so với nghiên cứu của Sinh and Long (2011) là khoản chi phí nhiên liệu chiếm tỷ trọng lớn nhất trong tổng cơ cấu chi phí hoạt động khai thác thủy sản $(66,6 \%)$. Điều này nói lền hoạt động khai thác thủy sản chịu chi phối lớn bởi yếu tố nhiên liệu và lực lượng lao động khai thác. Sự thay đổi tăng hoặc giảm giá nhiên liệu đầu vào, đặc biệt là xăng và dầu tác động rất lớn đến hoạt động sản xuất của ngư dân ở vùng biển Đông ĐBSCL.

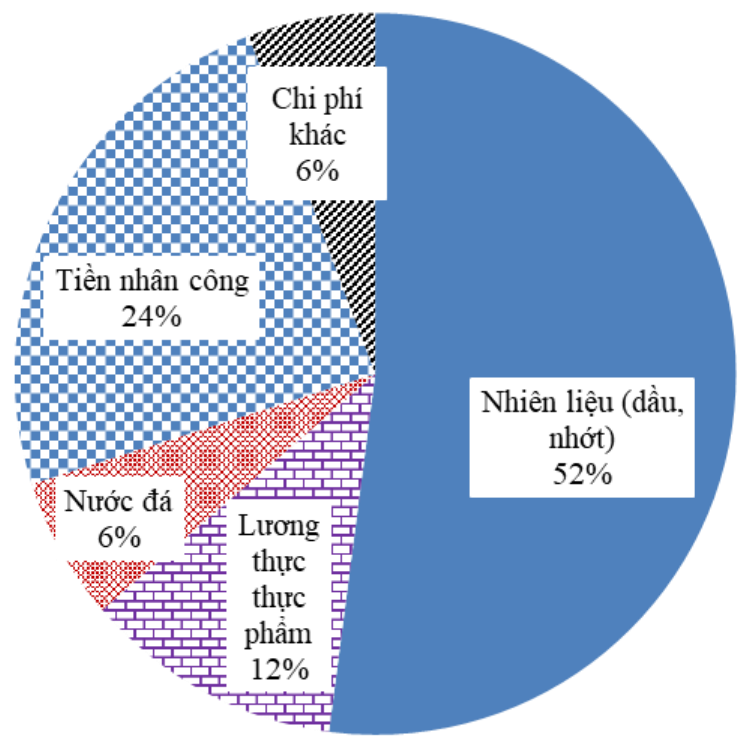

Hình 1. Cơ cấu chi phí biến đổi của nghề lưới kéo

Chi phí hoạt động khai thác của nghề lưới kéo ở vùng biển Đông ĐBSCL là 316 triệu đồng/năm, tương ứng mỗi chuyến biển ngư dân cần 10,7 triệu đồng/chuyến. Tổng doanh thu đạt trung bình 608 triệu đồng/năm. Doanh thu có dao động lớn (1981.507 triệu đồng/năm) vì phụ thuộc vào quy mô và 
thời gian khai thác của tàu. Nghề lưới kéo có lợi nhuận trung bình là 292 triệu đồng/năm và tỷ suất lợi nhuận là 1,0 lần. Kết quả nghiên cứu trước đây cho thấy thu nhập từ hoạt động khai thác thủy sản đã góp phần nâng cao đời sống của ngư dân vùng ven biển. Thu nhập từ nghề lưới kéo quy mô nhỏ ỏ ĐBSCL mang lại 124 triệu đồng/năm (Sinh and Long, 2011) và thu nhập từ nghề lưới kéo ven bờ ở tỉnh Bạc Liêu bình quân là 510 triệu đồng/năm (Hồng Văn Thưởng và ctv., 2014). Thực tế cho thấy hoạt động khai thác thủy sản là một trong những hoạt động sản xuất mang lại nguồn thu nhập cho ngư dân vùng ven biển. Theo Huỳnh Văn Hiền và ctv. (2019), nghề lưới kéo vùng ven biển ĐBSCL đã đóng góp khoảng 86,7\% thu nhập của các hộ khai thác thủy sản vùng ven biển. Thu nhập của ngư dân chịu ảnh hưởng lớn từ sự suy giảm nguồn lợi thủy sản, điều kiện thời tiết và giá cả tiêu thụ sản phẩm thủy sản khai thác. Tỷ suất lợi nhuận (tỷ số giữa tổng lợi nhuận với tổng chi phí hoạt động khai thác) bình quân của nghề lưới kéo dao động từ 0,96 lần.

\section{Bảng 5. Chi phí, doanh thu và lọi nhuận của nghề lưới kéo}

\begin{tabular}{lrrr}
\hline Thông tin & Trung bình $(\mathbf{n}=\mathbf{6 0})$ & Độ lệch chuẩn & Dao động \\
\hline Tổng chi phí (triệu đồng/năm) & 316,2 & 128,1 & $111,1-717,3$ \\
Tổng doanh thu (triệu đồng/năm) & 607,8 & 251,9 & $197,5-1.507$ \\
Tổng lợi nhuận (triệu đồng/năm) & 291,6 & 172,7 & $27,9-850,3$ \\
Tỷ suất lợi nhuận (lần) & 0,96 & 0,52 & $0,14-2,13$ \\
\hline
\end{tabular}

(Nguồn: Số liệu khảo sát, 2020)

Sản phẩm thủy sản khai thác từ tàu lưới kéo ở vùng biển Đông ĐBSCL được bán trực tiếp cho các vựa và thương lái thu mua $(100 \%)$. Những nghiên cứu trước đây cho thấy sản phẩm thủy sản khai thác ở ĐBSCL chủ yếu được bán trực tiếp cho các vựa và thương lái thu mua và một phần nhỏ bán cho các tàu thu mua hải sản trên biển (Nguyễn Trọng Tuy và ctv., 2011; Nguyễn Trung Vẹn và ctv., 2013), riêng sản phẩm thủy sản khai thác từ các tàu lưới kéo ven bờ chỉ bán cho các vựa thu mua. Điều này cho thấy các vựa và thương lái thu mua có vai trò rất lớn trong việc tiêu thụ sản phẩm thủy sản khai thác.

\subsection{Hiệu quả kỹ thuật của nghề lưới kéo}

\subsubsection{Uớc luợng hiệu quả kỹ thuật của nghề} luoói kéo

Kết quả ước lượng hàm sản xuất và các yếu tố ảnh hưởng đến phi hiệu quả kỹ thuật của nghề lưới kéo vùng biển Đông ĐBSCL được thể hiện Bảng 6 . Doanh thu mang về từ khai thác thác thủy sản trong năm của nghề lưới kéo chịu sự tác động chủ yếu từ số ngày khai thác và chiều dài của ngư cụ, trong khi lực lượng lao động trên tàu có tác động đến doanh thu nhưng chưa đủ mạnh.

Số ngày khai thác cho một chuyến biển của nghề lưới kéo có hệ số ước lượng có ý nghĩa về mặt thống kê ở mức ý nghĩa $10 \%$ và có tương qua âm với tổng doanh thu. Điều này đã thể hiện phần nào là thời gian cho chuyến biển dài hay ngắn có ảnh hưởng rất lớn đến thu nhập của ngư dân nghề lưới kéo với điều kiện các yếu tố khác không đổi. Kết quả nghiên cứu này có sự tương đồng với kết quả nghiên cứu của Sharma and Leung (1999) ở nghề câu đường và Pascoe et al. (2001) ở nghề lưới kéo. Điều này có thể giải thích là (1) ảnh hưởng từ nguồn lợi thủy sản ven bờ, tức thời gian cho chuyến biển càng dài ở nghề lưới kéo, đồng nghĩa chi phí hoạt động khai thác càng tăng thì sản lượng khai thác, đặc biệt là loài có kích cỡ nhỏ và giá trị thấp (cá tạp) có xu hướng tăng; (2) chất lượng sản phẩm thủy sản, là khi thời gian trên biển càng dài thì chất lượng sản phẩm có xu hướng giảm do cách thức bảo quản của ngư dân chủ yếu là ướp nước đá và muối, trong khi các ngư dân bán chủ yếu sản phẩm khai thác ngay tại cảng cho các vựa và thương lái.

Chiều dài của ngư cụ khai thác có tác động lớn đến hiệu quả khai thác của nghề lưới kéo ở vùng biển Đông ĐBSCL. Hệ số ước lượng của chiều dài lưới có ý nghĩa về mặt thống kê ở mức ý nghĩa $5 \%$ và tương quan dương khi các yếu tố khác không đổi. Kết quả này tương đồng với kết quả nghiên cứu của các nghiên cứu của Kompas et al. (2004), Truong et al. (2011) trong hoạt động khai thác thủy sản là có thể tăng chiều dài ngư cụ nhằm mang lại hiệu quả khai thác cao hơn, thông qua kết hợp ngư cụ và sự giúp đỡ nhân lực trên tàu cùng nghề, cũng góp phần làm cho lao động khai thác làm việc tích cực và có trách nhiệm hơn. 
Bảng 6. Kết quả ước lượng hàm sản xuất và các yếu tố phi hiệu quả sản xuất

\begin{tabular}{|c|c|c|c|}
\hline Thông tin & Hệ số ước lượng & Giá trị kiểm định $\mathrm{t}$ & \\
\hline \multicolumn{4}{|l|}{ 1. Hàm sản xuất } \\
\hline Hằng số & 4,839 & 4,053 & **** \\
\hline lnngaykhaithac $\left(X_{I}\right)$ & $-0,972$ & $-1,726$ & $*$ \\
\hline $\ln$ laodong $\left(X_{2}\right)$ & 0,109 & 0,111 & \\
\hline $\ln l$ lui $\left(X_{3}\right)$ & 2,076 & 2,276 & *** \\
\hline $\operatorname{Ln} X_{1}^{2}$ & $-0,108$ & $-2,815$ & $* *$ \\
\hline $\ln X_{2}^{2}$ & $-0,739$ & $-2,353$ & $* *$ \\
\hline $\ln X_{3}^{2}$ & $-0,903$ & $-3,407$ & $* * *$ \\
\hline $\ln X_{1} * \ln X_{2}$ & 0,112 & 0,369 & \\
\hline $\ln X_{1} * \ln X_{3}$ & 0,578 & 2,934 & $* * *$ \\
\hline $\ln X_{2} * \ln X_{3}$ & 0,446 & 0,914 & \\
\hline \multicolumn{4}{|l|}{ 2. Hàm phi hiệu quả } \\
\hline Hằng số & $-1,721$ & $-2,117$ & *** \\
\hline Kinh nghiệm (năm) & $-0,057$ & $-2,686$ & $* *$ \\
\hline Học vấn của thuyền trưởng (lớp) & 0,088 & 2,416 & $* *$ \\
\hline Tuổi thuyền trưởng (năm) & 0,053 & 3,196 & $* * *$ \\
\hline Công suất $(\mathrm{CV})$ & $-0,010$ & $-1,483$ & \\
\hline Tuổi tàu (năm) & 0,073 & 1,610 & $*$ \\
\hline Nguồn vốn (1- có vay; 0- Không) & $-0,518$ & $-2,253$ & *** \\
\hline$\sigma^{2}$ & 0,081 & 2,880 & $* *$ \\
\hline r & 0,484 & 2,762 & $* *$ \\
\hline
\end{tabular}

Chú thich: ${ }^{* * *},{ }^{* *},{ }^{*}$ biểu diễn các múc ý nghĩa 1\%, 5\%, 10\%

Hệ số ước lượng của yếu tố lao động trên tàu không có ý nghĩa về mặt thống kê ở mức ý nghĩa $10 \%$, nghĩa là số lượng lao động trên tàu có tác động thuận biến đến doanh thu của ngư dân nghề lưới kéo ven bờ nhưng chưa đủ mạnh. Kirkley et al. (1995) và Jamnia et al. (2013) cũng nhận định lực lượng lao động trên tàu có tác động tích cực đến doanh thu của ngư dân khai thác thủy sản. Nguyên nhân là nghề lưới kéo ở vùng biển Đông ĐBSCL sử dụng lực lượng lao động gia đình là chủ yếu, bởi nguồn lực này có trách nhiệm với hoạt động sinh kế của họ. Bên cạnh đó, thu nhập của một số lao động thuê mướn được trả công lao động theo tỷ lệ phần doanh thu của chuyến biển, góp phần nâng cao vai trò và trách nhiệm khai thác, mang lại thu nhập cao.

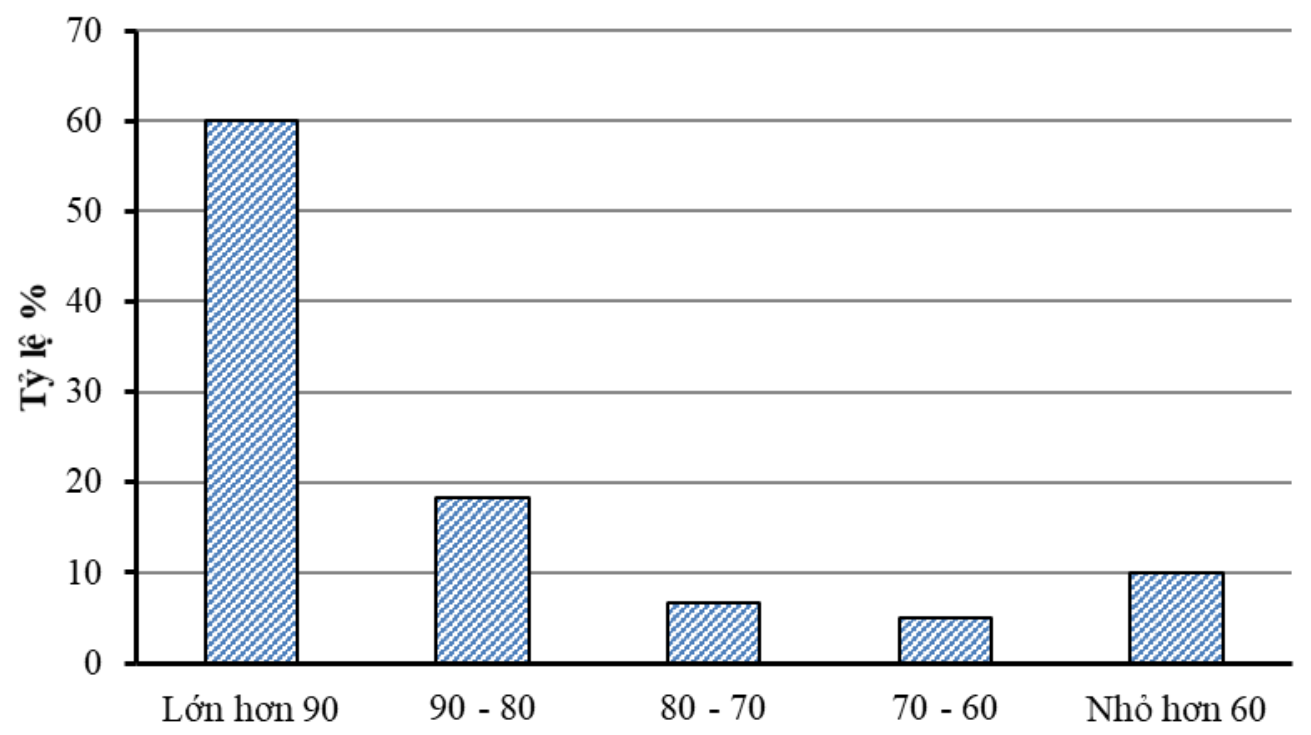

Hình 2. Mức hiệu quả kỹ thuật của nghề lưới kéo vùng biển Đông ở ĐBSCL 
Mức hiệu quả kỹ thuật của các tàu lưới kéo vùng biển Đông ĐBSCL được thể hiện ở Hình 1. Mức hiệu quả kỹ thuật của các tàu lưới kéo đạt trung bình 86,3 và sự chênh lệch mức hiệu quả giữa các tàu đạt cao nhất và thấp nhất là khá lớn, dao động từ $47,9 \%$ đến $97,9 \%$. Trong đó, số tàu lưới kéo đạt mức hiệu quả kỹ thuật cao hơn $90 \%$ chiếm tỷ lệ $60 \%$ số tàu khai thác. Kết quả nghiên cứu của các tác giả trước đây là Herrero et al. (2006); Sharma and Leung (1999) và Tingley et al. (2005) trong hoạt động khai thác cũng xác định mức hiệu quả kỹ thuật dao động từ $65-80 \%$. Điều này cho thấy mức hiệu quả kỹ thuật của tàu lưới kéo vùng biển Đông ĐBSCL đạt ở mức cao, nhưng cần cải thiện thêm để đạt được hiệu quả tối đa.

\subsubsection{Các yếu tố ảnh huởng đến hiệu quả kỹ thuật của nghề lưới kéo}

Bảng 6 cho thấy đặc điểm của thuyền trưởng (kinh nghiệm, học vấn và tuổi) có ảnh hưởng đến hiệu quả kỹ thuật của nghề lưới kéo vùng biển Đông ĐBSCL. Trình độ học vấn và tuổi của thuyền trưởng có hệ số ước lượng có ý nghĩa về mặt thống kê ở mức ý nghĩa $5 \%$ và $10 \%$ tương ứng và tương quan nghịch biến với hiệu quả kỹ thuật. Tức là thuyền trưởng có trình độ học vấn càng cao hoặc càng lớn tuổi thì hiệu quả khai thác không cao. Trong khi đó, yếu tố về kinh nghiệm khai thác có vai trò quyết định đến hiệu quả khai thác, tức thuyền trưởng càng có nhiều kinh nghiệm trong khai thác thì giúp nâng cao hiệu quả khai thác hơn. Hệ số ước lượng của kinh nghiệm khai thác của thuyền trưởng có ý nghĩa mặt thống kê ở mức ý nghĩa 5\%. Pascoe and Coglan (2002) đánh giá sự kém hiệu quả kỹ thuật trong khai thác thủy sản là do ít nhiều sự tác động của người thuyền trưởng. Cụ thể là người thuyền trưởng có thể gặp hạn chế sự quyết định nhanh trong điều kiện nguồn lợi thủy sản thay đổi.

Liên quan đến đặc điểm của tàu và ngư cụ, hệ số ước lượng của công suất máy tàu có tương quan nghịch biến với phi hiệu quả kỹ thuật của nghề lưới kéo, nghĩa là khi tăng công suất máy tàu thì giúp phần kém hiệu quả kỹ thuật giảm, tức là càng nâng cấp công suất máy tàu sẽ giúp doanh thu khai thác của ngư dân nghề lưới kéo được cải thiện, với điều kiện các yếu tố khác không đổi. Thực tế, nghề lưới kéo là nghề khai thác di dộng và đánh bắt chủ yếu các loài cá ở tầng đáy và gần đáy, tàu cần sức kéo lớn nên công suất máy tàu là một trong những yếu tố có ảnh hưởng hiệu quả khai thác. Tàu có công suất máy lớn giúp cho ngư dân có thể di chuyển nhanh và đánh bắt cá được ở vùng nước sâu. Kompas et al. (2004) và Truong et al. (2011) nhấn mạnh công suất máy tàu càng lớn thì hiệu quả khai thác càng tăng. Hơn nữa là tuổi của tàu có ảnh hưởng nghịch biến với hiệu quả kỹ thuật của nghề lưới kéo và có ý nghĩa về mặt thống kê ở mức ý nghĩa $10 \%$. Pascoe \& Coglan (2002) cũng tìm ra sự khác nhau hiệu quả khai thác thủy sản là do tuổi của tàu khai thác bên cạnh yếu tố công nghệ và lực lượng lao động trên tàu. Điều này có thể giải thích là tàu cũ có thể gặp vấn đề trang thiết bị, kích cỡ tàu, tiêu tốn nhiên liệu, thời gian và chi phí sửa chữa. Cho nên, tuổi của tàu có xu hướng tăng thì hiệu quả khai thác có chiều hướng giảm.

Nguồn vốn vay được sử dụng trong hoạt động khai thác có thể từ nhiều nguồn khác nhau, chủ yếu từ nguồn vốn vay và nguồn vốn tự có (vốn tích lũy, người thân, các vựa thu mua). Kết quả ước lượng cho thấy vốn khai thác của ngư dân nghề lưới kéo từ nguồn vốn vay có hiệu quả hơn và có ý nghĩa về mặt thống kê ở mức ý nghĩa $5 \%$. Nguyên nhân là khả năng tiếp cận nguồn vốn vay từ các tổ chức cung cấp vốn là rất hạn chế do cần nhiều tài sản thế chấp đảm bảo tiền vay. Chính điều này, ngư dân khai thác phải ứng vốn từ các cơ sở vựa và thương lái thu khi mà nguồn vốn tích lũy của họ không đảm bảo cho chuyến ra biển. Điều này làm ngư dân không quyết định được giá bán nên doanh thu giảm.

Nhìn chung, kết quả ước lượng hiệu quả kỹ thuật cho thấy ngư dân nghề lưới kéo ở vùng biển Đông ĐBSCL có tiềm năng cải thiện hiệu quả khai thác, mặc dù có đến $60 \%$ số tàu khai thác kết hợp các yếu tố đầu vào trong khai thác gần đạt hiệu quả kỹ thuật tốt nhất. Ngư dân nghề lưới kéo vùng biển Đông ĐBSCL có thể đầu tư nâng cấp công suất máy tàu kết hợp với đánh bắt theo nhóm đội nhằm hỗ trợ khai thác có hiệu quả. Đối với các ngư dân có điều kiện đầu tư tàu mới hoặc tàu lớn hơn để khai thác vùng xa bờ mang lại hiệu quả tốt hơn, phù hợp với chính sách phát triển của ngành là khuyến kích ngư dân chuyển đổi để khai thác thủy sản vùng xa bờ. Mặt khác, ngư dân có thể nâng cao thu nhập từ việc tiêu thụ sản phẩm khai thác tại cảng thông qua phát triển kênh thị trường. Ngư dân có thể điều chỉnh hoạt động đánh bắt và phương thức đánh bắt phù hợp như khai thác có tính chọn lọc các loài cá có giá trị hoặc kích cỡ lớn, với việc tạo ra các sản phẩm thủy sản có giá trị gia tăng thay cho việc bán sản phẩm tươi sống. Điều đáng ngại là hoạt động khai thác thủy sản không chỉ phụ thuộc rất lớn vào điều kiện thời tiết và nguồn lợi thủy sản, mà còn phụ thuộc vào việc tiêu thụ sản phẩm thủy vì phần lớn việc tiêu thụ này phụ thuộc vào nhóm trung gian. Sản phẩm thủy sản được bán trực tiếp cho các vựa và thương lái thu mua và họ ít quyết định được giá cả. 


\section{KẾT LUẬN}

Sản lượng thủy sản khai thác tàu lưới kéo là 643 $\mathrm{kg} /$ chuyến biển và 18,9 tấn/năm và năng suất khai thác là $352 \mathrm{~kg} / \mathrm{CV} / \mathrm{năm}$. Chi phí hoạt động khai thác là 316 triệu đồng/năm với thu nhập mang về 608 triệu đồng/năm, lợi nhuận là 292 triệu đồng/năm và tỷ suất lợi nhuận là 1,00 lần.

Mức hiệu quả kỹ thuật của nghề lưới kéo vùng biển Đông ĐBSCL đạt mức khá cao (86,3\%). Các đặc điểm của thuyền trưởng, tàu khai thác và nguồn vốn sản xuất là các yếu tố quan trọng có tác động đến phi hiệu quả kỹ thuật trong khai thác thủy sản. Thuyền trưởng tích lũy được nhiều kinh nghiệm trong khai thác thủy sản thì có khuynh hướng hiệu quả hơn so với người ít trải nghiệm, trong khi tuổi và trình độ học vấn càng cao thì khai thác hải sản có xu hướng không hiệu quả. Tàu khai thác mới có hiệu quả hơn so với tàu cũ cũng như nguồn vốn vay có hiệu quả cao hơn so với vốn tự có.

Kết quả nghiên cứu này cung cấp thông tin cơ bản về hiệu quả kỹ thuật của nghề lưới kéo nhưng vẫn còn một số đặc điểm về trữ lượng nguồn lợi thủy sản, mùa vụ và công nghệ của thiết bị sử dụng trên tàu chưa được quan tâm. Mặt khác, sự quản lý nghề cá mang tính ổn định và phát triển khi hiệu quả kỹ thuật, hiệu quả phân phối và hiệu quả kinh tế được xem xét. Các nghiên cứu tiếp theo phân tích đầy đủ hơn là cần thiết, giúp việc quản lý nghề cá ven bờ ngày càng phát triển ổn định và phù hợp với chính sách phát triển của ngành.

\section{LỜI CẢM TẠ}

Đề tài này được tài trợ bởi Dự án Nâng cấp Trường Đại học Cần Thơ VN14-P6 bằng nguồn vốn vay ODA từ chính phủ Nhật Bản.

\section{TÀI LIỆU THAM KHẢO}

Coelli, T.J., Tao, D.S.P., O’Donnell, C.J., \& Battese, G.E. (2005). An introduction to efficiency and productivity Analysis second edition. Springer Science \& Business Media.

Herrero, I., Pascoe, S., \& Mardle, S. (2006). Mix efficiency in a multi-species fisheries. Journal of Productivity Analysis, 25(3), 231-241. https://doi.org/10.1007/s11123-006-7641-9

Hiệp hội Chế biến và Xuất khẩu thủy sản Việt Nam [VASEP] (2020, 05/10). Xuất khẩu thủy sản năm 2019. http://vasep.com.vn/Tin-

Tuc/1200_58730/Xuat-khau-thuy-san-nam-2019can-dich-voi-86-ty-USD.htm

Hiệp hội Chế biến và Xuất khẩu thủy sản Việt Nam [VASEP]. (2018). Báo cáo ngành hải sản khai thác Việt Nam năm 2008 đến 2017. 47 trang.
Hồng Văn Thưởng, Hà Phước Hùng \& Hồng Thị Hải Yến. (2014). Hiện trạng khai thác và quản lý nguồn lợi hải sản ở tỉnh Bạc Liêu. Tạp chí Khoa học Truò̀ng Đại học Cần Tho, 30, 37-44.

Huỳnh Văn Hiền, Đặng Thị Phượng \& Trần Đắc Định. (2019). Khía cạnh kinh tế - xã hội của các nghề khai thác thủy sản vùng cửa sông Cửu Long. Tạp chi Khoa hoc Công nghệ Nông nghiệp Việt Nam, 8(105), 122-128.

Jamnia, A.R., Mazloumzadeh, S.M., \& Keikha, A.A. (2014). Estimate the technical efficiency of fishing vessels operating in Chabahar region, Southern Iran. Journal of the Saudi Society of Agricultural Sciences, 14(1), 26-32. https://doi.org/10.1016/j.jssas.2013.04.005

Kirkley, J.E., Sqires, D., \& Strand, I.E.S. (1995). Assessing technical efficiency in commercial fisheries: The Mid-Atlantic sea scallop Fishery. American Journal of Agricultural Economics, 77(3), 686-697. https://doi.org/10.2307/1243235

Kompas, T., Che, T.N., \& Grafton, R.Q. (2004). Technical efficiency effects of input controls: evidence from Australis's banana prawn fishery. Applied Economics, 36(15), 1631-1641. http://dx.doi.org/10.1080/0003684042000218561

Nguyễn Trọng Tuy, Lê Xuân Sinh \& Đặng Thị Phượng. (2011, tháng 12 ngày 16). Thục trạng và môt số giải pháp trong khai thác và bảo vệ nguồn lợi hải sản ở tỉnh Tiền Giang [Báo cáo tóm tắt]. Kỷ yếu Hội nghị khoa học thủy sản toàn quốc, Trường Đại học Nông Lâm, Thành phố Hồ Chí Minh.

Nguyễn Trung Vẹn, Lê Xuân Sinh \& Đặng Thị Phượng. (2013, tháng 6 ngày 6 -7). Phân tích hiệu quả khai thác hải sản ở Đồng bằng sông Cưu Long [Báo cáo tóm tắt]. Hội nghị Khoa học trẻ ngành thủy sản toàn quốc lần thứ IV, Trường Đại học Nông Lâm, Thành phố Hồ Chí Minh.

Pascoe, S., \& Coglan, L. (2002). The contribution of unmeasurable inputs to fisheries production: An analysis of technical efficiency of fishing vessels in the English Channel. American Journal of Agricultural Economics, 84(3), 588-597. https://doi.org/10.1111/1467-8276.00321

Pascoe, S., Andersen, J.L., \& Wild, J.W.D. (2001). The impact of management regulation on the technical efficiency of vessels in the Dutch beam trawl fishery. European review of Agricultural Economics, 28(2), 187206. https://doi.org/10.1093/erae/28.2.187

Sharma, K.R., \& Leung, P. (1999). Technical efficiency of the longline fishery in Hawaii: an application of a stochastic production frontier. Marine Resource Economics, 13(4), 259-274. https://doi.org/10.1086/mre.13.4.42629241

Sinh, L.X., \& Long, N.T. (2011). Status and perception of coastal small-scale trawling fishers 
in the Mekong Delta of Vietnam. International Journal of Fisheries and Aquaculture, 3(2), 26-34.

Tingley, D., Pascoe, S., \& Coglan, L. (2005). Factors affecting technical efficiecy in fisheries: stochastic production frontier versus data envelopment analysis approaches. Fisheries Research, 73(3), 363-376.

https://doi.org/10.1016/j.fishres.2005.01.008
Tổng cục Thống kê (2020). Số liệu thống kê. https://www.gso.gov.vn/so-lieu-thong-ke/

Truong, N.X., Vassdal, T., Ngoc, Q.T.K., Anh, N.T.K., \& Thuy, P.T.T. (2011). Technical efficiency of Gillnet fishery in Da Nang, Vietnam: Application of stochastic production frontier. Fish for the People, 9(1), 26-39. 